\section{Dearl Reatler:}

This volume 14 of Scientific Drilling presents you with three new reports (pp. 4, 30, and 34) of the Nankai Trough Seismogenic Zone Experiment (NanTroSEIZE). This major project using the riser-drilling-capable drilling vessel Chikyu is now approaching the final and ambitious goal of drilling deep into a fault system that is known to repeatedly generate magnitude $8+$ earthquakes. By the time this volume arrives at your desk, drilling of the final and deep riser hole will have begun. Actually, that was scheduled to have happened one year ago, but damage to Chikyu by the 11 March 2011 magnitude 9.0 earthquake and related tsunami caused a delay. Also, the Integrated Ocean Drilling Program (IODP) made it a priority to conduct a rapid response drilling into the fault that moved during the megaquake. The extremely demanding drilling in nearly 7000 meters of water within the Japan Trench was completed by Chikyu during July 2012 with successful logging, coring, and borehole observatory installation as much as 800 meters below seabed (p. 77). We hope to bring a report on this scientific and technological feat soon.

Lake drilling continues to be a highly important and successful component of the International Continental Scientific Drilling Program (ICDP). On page 18 we issue a report on the Lake Van, eastern Turkey drilling campaign. With its location and long history, it is well positioned to provide an important regional climate and environmental record including geohazards (earthquake history). A workshop report (p. 72) on the potential for lake deposit drilling near Mexico City is another example of how regionally important information regarding the environment (climate, water supply, and seismicity) can be amassed by scientific drilling and provide a context for the interpretation of much shorter historical records of environmental change.

As editors, we feel obliged to inform you that essential IODP funding of this journal is not yet secured beyond spring 2013. In order to establish viable funding for operations of the JOIDES Resolution, the U.S. National Science Foundation (NSF) will assess the merits of every component of the current program before deciding on what functions will roll over into the new International Ocean Discovery Program, which is planned to replace the current IODP by October 2013. The science plan for the new IODP is well established (www.iodp.org/science-plan-for-2013-2023) and, with Brazil recently joining the current IODP, is now supported by as many as 26 nations. What is also known at this point is that the U.S. commitment to the new IODP is secured for a one-year period to start in October 2013. This new program will not be centrally managed like the current IODP, but work more like a confederation of programs under the umbrella of a common science plan (p. 76). The feasibility of the new program structure and its funding model will need to prove successful before a final and long-term commitment of the JOIDES Resolution to the new IODP is made by the NSF.

So, please stay tuned for both important new science reports and program news in the spring 2013 issue of Scientific Drilling. It could be a collector's item-hopefully because of exciting good news on all fronts within scientific drilling.

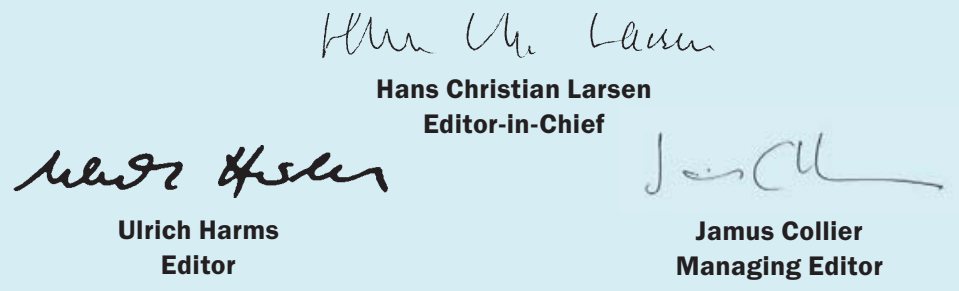

Front cover: Fine tephra layer that has been deformed in a microfold, indicating slumping, potentially induced by seismic shaking. (see page 26)

Left inset: Adding a clinometer data logger to a sensor carrier for the long-term borehole monitoring system (LTBMS) during Exp. 332. (see page 34)
Scientific Drilling is a semiannual journal published by the Integrated Ocean Drilling Program (IODP) with the International Continental Scientific Drilling Program (ICDP). The editors welcome contributions on any aspect of scientific drilling, including borehole instruments, observatories, and monitoring experiments. The journal is produced and distributed by the Integrated Ocean Drilling Program Management International (IODP-MI) for the IODP under the sponsorship of the U.S. National Science Foundation, the Ministry of Education, Culture, Sports, Science and Technology of Japan, and other participating countries. The journal's content is partly based upon research supported under Contract OCE-0432224 from the National Science Foundation.

Electronic versions of this publication and information for authors can be found at http://www.iodp.org/scientific-drilling/ and http://www.icdp-online.org/scientificdrilling/. Printed copies can be requested from the publication office.

IODP is an international marine research drilling program dedicated to advancing scientific understanding of the Earth by monitoring and sampling subseafloor environments. Through multiple drilling platforms, IODP addresses its four principal challenges: Climate and Ocean Change, Biosphere Frontiers, Earth Connections, and Earth in Motion.

ICDP is a multi-national program designed to promote and coordinate continental drilling projects with a variety of scientific targets at drilling sites of global significance.

\section{Publication Office}

IODP-MI, Tokyo University of Marine

Science and Technology,

Office of Liaison and Cooperative

Research 3rd Floor,

2-1-6, Etchujima, Koto-ku, Tokyo

135-8533, JAPAN

Tel: +81-3-6701-3180

Fax: +81-3-6701-3189

e-mail: journal@iodp.org

url: www.iodp.org/scientific-drilling/

\section{Editorial Board}

Editor-in-Chief Hans Christian Larsen

Managing Editor Jamus Collier

Editor Ulrich Harms

Send comments to:

journal@iodp.org

Editorial Review Board

Gilbert Camoin, Keir Becker,

Hiroyuki Yamamoto, Naohiko Ohkouchi,

Stephen Hickman, Christian Koeberl,

Julie Brigham-Grette, Maarten DeWit, and Thomas Wiersberg

\section{Copy Editing}

Glen Hill, Obihiro, Japan

Layout, Production and Printing Mika Saido (IODP-MI), and Obun Printing, Co. Inc., Tokyo, Japan

IODP-MI

Tokyo, Japan

www.iodp.org

Program Contact: Miyuki Otomo

motomo@iodp.org

ICDP

GFZ German Research Center For

Geosciences

www.icdp-online.org

Program Contact: Ulrich Harms

ulrich.harms@gfz-potsdam.de

All figures and photographs courtesy of the IODP or ICDP, unless otherwise specified. 